\title{
Effects of Cyclic Loading on the Rheological Properties of Sandstones
}

\author{
Jindřich Šancer, ${ }^{1 *}$, Martin Štrejbar, ${ }^{1}$, Aneta Maleňáková ${ }^{1}$ \\ 1 Institute of Mining Engineering and Safety, Faculty of Mining and Geology, VŠB - Technical University of Ostrava, Czech \\ Republic
}

Received 8 April 2011 ; accepted 6 June 2011

\begin{abstract}
This paper presents some results of the laboratory tests on the time-dependent behaviour of three types of sandstone. Research into the rheological properties of rocks is mostly done under static (quasistatic) loading. In nature, however, rocks are also often subjected to cyclic (vibration) loading as a result of vibrations from traffic or the propagation of seismic waves due to, for example, earthquakes, rock bursts, blasting operations and such like. On this account, the research presented is focused on the study of rheological rock properties during vibration (cyclic) loading.

The tests of the rheological properties of a cyclic load were conducted both in creep regime and in relaxation regime, at various levels of average load or strain and for various parameters of vibration (frequency, amplitude). The measured values of different parameter settings were compared and evaluated so that it was possible to set the dependence of cyclical rock loading in the rheological regime. For the purpose of the comparison of rock behavior during vibration and static loading, other tests were also carried out.

The results of the research show that, in the course of cyclical loading, the rock rheological properties depend, to a significant extent, on the parameters of this loading, especially the amplitude and frequency.
\end{abstract}

Keywords: creep $\cdot$ relaxation $\bullet$ fatigue $\cdot$ uniaxial cyclic loading

(C) Versita Sp. z o.o.

\section{Introduction}

Rock rheology studies the changes of stress-strain characteristics of rocks through time under otherwise constant terms and conditions. The research in this area is linked to e.g. depositing radioactive waste in underground premises where long-term stability is required. In spite of the evergrowing significance of detailed research into the rock rheological behaviour, no established methodology has

*E-mail: jindrich.sancer@vsb.cz been developed, so far, for testing the time-related rock properties.

Perhaps the highest diversity of testing can be found in the observation of rheological rock properties under cyclical loading where the loading parameters can change. According to [1], there can be two types of cyclical loading, i.e. type 1 where the loading changes in cycles between two firmly set limit boundaries, and type 2 where the loading is gradually increased at each following cycle.

This research was carried out at uniaxial loading according to type 1 . This type of loading can be simulated on a modern press, MTS 816 Rock Test System, purchased by VŠB-Technical University of Ostrava. This system is 
able to produce the maximum compression force of 1015 $\mathrm{kN}$ and the maximum tensile force of $650 \mathrm{kN}$. The stiffness of the press is determined at $26.10^{8} \mathrm{~N} / \mathrm{m}$. For measuring the deformation an internal LVTD was used, placed in the actuator. Measured data were corrected by the stiffness constant of the press machine. The resolution of the internal LVTD is $10^{-4} \mathrm{~mm}$. A more detailed characterization of the test system is described in [2-4] and is therefore not repeated here.

In light of the possible application of the results of this project for rock bursts, the measurements have been only carried out with sedimentary rocks, predominantly sandstones. The carboniferous sandstone (uniaxial compressive strength $80-120 \mathrm{MPa}$ ) taken from the boreholes in the $\mathrm{OKR}$ coal mines have shown considerable variability in their mechanical properties, making evaluation of the results quite difficult. Therefore, the decision was made to carry out some tests with other sandstones which have lower variability. These sandstones were Godulský (from quarry Řeka, $140 \mathrm{MPa}$ ) and Bělohradský (42 MPa). More information about the Godula sandstone can be found in [5]. Tests of rheological properties at a cyclic load were conducted both in creep regime and in relaxation regime, for various levels of average load or strain and for various parameters of vibration (frequency, amplitude).

The measured values of different parameter settings were compared and evaluated so that it was possible to set the dependence of cyclical rock loading in the rheological regime. For a mutual comparison of rock behavior during vibration and static loading, other tests were also made during the static loading.

\section{Overview of previous studies}

The study of rheological rock properties is a very complex issue owing to the rock heterogenity, anisotropy and many other relevant agents, for example, temperature, humidity, the quality of rock samples, the type of loading, and such like. The background literature shows that, although a lot of research centres have been dealing with this issue, it still remains to be clarified. There has been a great amount of research, the results of which are very difficult to compare due to the absence of an accurate standard of methodology (a norm) applicable to testing and evaluating procedures for determining the rheological properties in laboratory conditions. Each study differs, for example, in the length of observation which classifies the tests either as short-term (lasting for several hours) or longterm (lasting for days or months), or the type of loading (for example, uniaxial, triaxial, static, cyclical, compressive stress, bending, etc.) Falaleev [6] tried to classify the rocks according to the rock creep, into five categories based on the results of several studies. In this study, he found that the rock rheological properties at static loading differed significantly according to the type of loading: uniaxial compressive stress or bending. For example, sandstone exposed to a uniaxial compressive stress behaves as a rock little prone to creeping (category 1). On the other hand, when exposed to bending, it falls into categories 4 and 5, that is, rocks prone to creeping.

The results are much more diverse when observing the rock rheological properties at cyclical loading. In this type of loading regime, the rock is usually loaded at the pre-set average value (TSP - Target Set Point) around which it regularly oscillates at the amplitude, $A$ and frequency, f. All the loading parameters are kept constant and the changes of stress and deformation properties with time are observed.

This issue has been explored by a significantly smaller number of authors. One of the reasons is the far greater cost of laboratory equipment, for example, the necessity to own a press to generate the required loading. Due to high energy consumption, most research of this kind has been carried out only in the short-term. Almost all research carried out so far has proved that the rheological behaviour of rocks exposed to cyclical loading is similar to the behaviour at static loading. However, at cyclic loading, the rheological properties are more dynamic, the rock failure starts earlier and under lower loading levels [7-10]. There are various opinions about the cause of this phenomenon. Currently, most authors agree with the results first published by Scholtz and Koczynski [7], or later by Costin and Holcomb [8] or Gatelier et al. [1], which have shown that load cycling reduces rock strength, probably for reasons of combining cyclic fatigue and stress corrosion. According to $[11,12]$ stress corrosion is defined as time - dependent cracking in rock that depends on load, temperature and moisture.

According to Jeon et al. [13], stress corrosion is the reaction between strained silicate minerals and environmental agents at the crack tip in the rock, and is one of most important mechanisms of subcritical crack growth.

It is known that stress corrosion cracking occurs due to the characteristics of the surrounding environment, such as viscosity, pressure, temperature, humidity, $\mathrm{pH}$ and so on. Among these characteristics, the existence of water in the surrounding environment is closely related to the stress corrosion of rock [13].

Damjanac and Fairhurst [14] state that stress corrosion is often proposed as the most likely mechanism for timedependent strength degradation of brittle and crystalline 
rocks. There are two necessary conditions for stress corrosion activation: (1) the existence of fractures, and (2) tension at the fracture tips greater than the limit imposed by the stress-corrosion activation energy. Consequently, the long-term strength threshold of intact rock with no pre-existing fractures should be equal to or greater than the crack initiation stress (threshold level), which is in the range of $40 \%-60 \%$ of the short-term strength.

The effect of stress corrosion was implemented in a numerical model by Potyondy [15]. This model mimics the stress-dependent corrosion reaction that occurs in silicate rocks in the presence of water.

Obviously, the evaluation of rheological behavior during cyclic loading is far more complex compared to static loading, because the rock behaviour will be influenced not only by the parameters of cyclic loading but also, according to some authors, for example, $[9,16]$, by the waveform of cyclic loading.

Furthermore, the interpretation of results is often different. Most published data is related to the fatigue tests, with the aim to depict the fatigue $\mathrm{S}-\mathrm{N}$ curves which show the relation of loading stress, $\mathrm{S}$ to the number of cycles necessary to break the sample, $N[7,10]$. Most of these studies were carried out at very low frequencies, i.e. $0.1-0.01 \mathrm{~Hz}$. During the simulation of vibrations [caused, for example, as a consequence of vibrations from traffic, earthquakes or rock bursts], it is always necessary to carry out measurements at a higher speed of loading (frequency). This is because the number of cycles carried out within a given time grows in direct proportion to the growing frequency. It is more convenient to observe the rock transformation through time and to record the time at which it gets corroded. This type of evaluation regime enables one to more accurately determine the impact of frequency on the rheological rock behaviour. The results of measurements below have been evaluated in this regime.

\section{Stress Relaxation of Rocks}

Relaxation expresses the rock behaviour with stress at a constant strain, through time. When determining the relaxation of rocks, the strain, to which the initial stress $\sigma_{o}$ corresponds, is applied to the rock so that the change in acting stress at a constant strain can be found. The technical application of this test is considerably difficult owing to a necessity to maintain the constant strain; nevertheless the test system MTS 816 makes it possible to operate in this regime. A typical curve of rock relaxation at a static load as stated in the literature is provided in Figure 1.

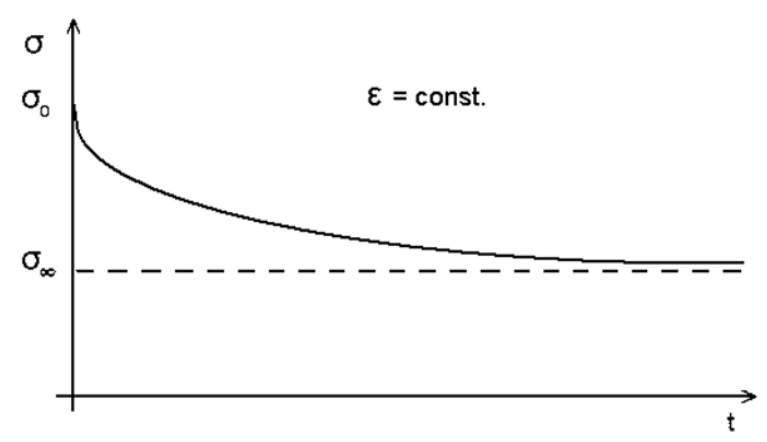

Figure 1. Typical curve of rock relaxation.

Peak/Valley Data

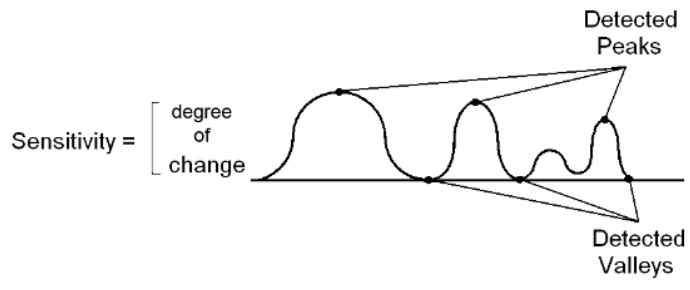

Figure 2. Principle of Peak/Valley data acquisition process.

As seen in the Figure, stress decreases with time and its' value approximates asymptotically to a constant, which does not equal zero. During rock relaxation, a change in the ratio of elastic strain to plastic strain probably occurs throughout the course of a test. Plastic strain grows at the expense of elastic strain as the duration of loading increases; the sum of plastic strain and elastic strain remains constant. To maintain the plastic strain, less force is needed and thus a reduction in measured stress is given.

\subsection{Stress Relaxation of Rocks under Cyclic Loading}

Throughout the study into rock relaxation on the machine MTS 816, relaxation was carried out under cyclic (vibrational) loading. At this load, the sample was loaded to a certain mean value of deformation of TSP (Target Set Point), around which the value of strain constantly fluctuates sinusoidally with the set amplitude of strain at a chosen fluctuation frequency.

Data acquisition was done in the Peak/Valley regime. The Peak/Valey regime is a data acquisition process that 


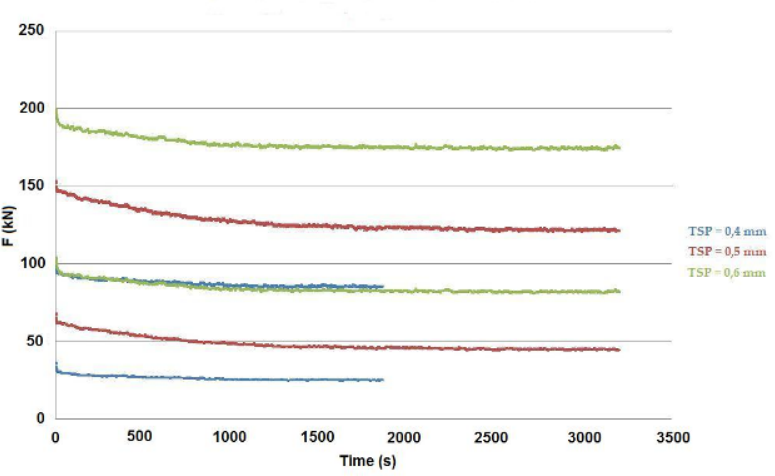

Figure 3. Comparison of sandstone relaxation curves at various TSPs.

records the data two times for each cycle. Setting a sensitivity value allows user to specify the amount the signal must change to detect a peak or valley. This allows users to adjust the Peak/Valley Acquisition process to ignore signal noise but still detect low amplitude signals. Once the sensitivity value is exceeded, the output of the master is monitored until the master signal reverses. The highest or lowest value is recorded until the master signal changes by the specified sensitivity value. The principles of the acquisition process are presentedin Figure 2.

In the framework of research into the relaxation of rocks under cyclic loading, tests at various setting of input values (TSP, amplitude, frequency) were carried out and those were then compared. In Figure 3 relaxation curves for rocks under cyclic loading at various settings of TSP, but at a single amplitude, $A=0.1 \mathrm{~mm}$ and frequency, $\mathrm{f}=5 \mathrm{~Hz}$ are plotted. Each setting of the test is presented in Figure 3 for both peaks and valleys.

As evident in the Figure, the curves correlate to each other ("peak" curve at TSP of $0.4 \mathrm{~mm}$ begins at the almost identical value with that of "valley" curve at TPS of $0.6 \mathrm{~mm}$ ). Furthermore, as follows from the Figure, with an increasing level of deformation a larger range of force must be used to maintain the same amplitude. The relaxation curve is steeper with the increasing value of deformation.

Relaxation curves for various settings of amplitudes and frequencies of cyclic loading were compared (Figure 4). The stress, which is necessary to maintain the deformation, increases with increasing strain amplitude. The curve of peaks decreases steeper than the curve of valleys and the stress necessary to keep the adjusted amplitude of deformation, successively decreases. This effect is exaggerated if the amplitude value is increased.

The influence of frequency is noticeable in Figure 4. With increasing frequency of cyclic loading, the level of relax-

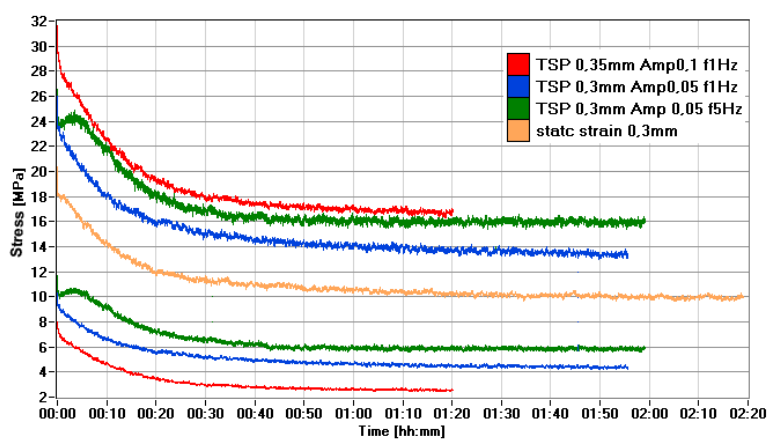

Figure 4. Relaxation of Bělohradský sandstone at various setting of cyclic loading.

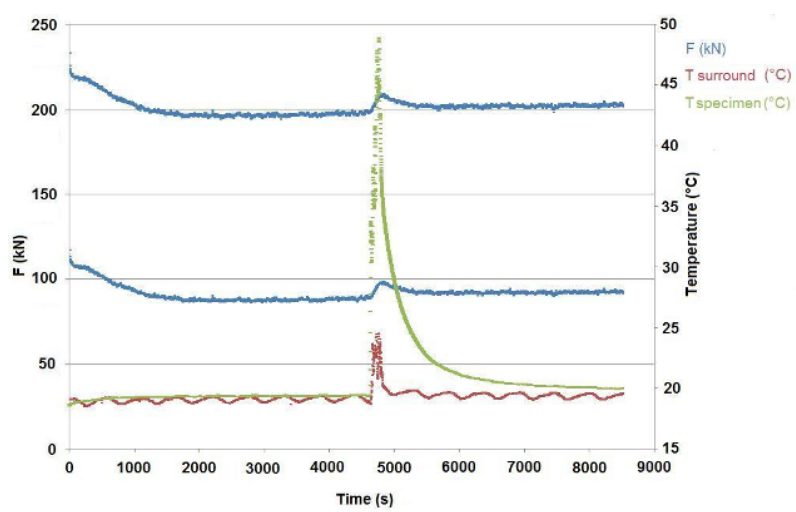

Figure 5. Effect of temperature on rock relaxation.

ation decreases (the decrease is less extreme/more gradual than at lower frequencies of loading).

With growing frequency then, apparently, illogical "opposite" behaviour of the relaxation curve is sometimes shown during the first minutes. We ascribe it to the heating of rock in the course of dynamic loading. For the verification of this theory, the temperature inside the rock specimen was measured by means of a thermocouple during one of the tests. The surrounding temperature was also measured. After more than one hour of relaxation (following the stabilization of the force), the rock specimen was heated with hot air, using an electric drier, and it was noted whether or not an increase in force, required for the maintenance of the set deformation, would occur. This test was conducted on a sample of carboniferous sandstone; the sinusoidal deformation behaviour fluctuation around the constant mean value, TSP $=0.5 \mathrm{~mm}$, with amplitude, $0.1 \mathrm{~mm}$ and frequency, $5 \mathrm{~Hz}$, was maintained. An example of a record from this test is presented in Figure 5.

An obvious moderate increase in the temperature of the 


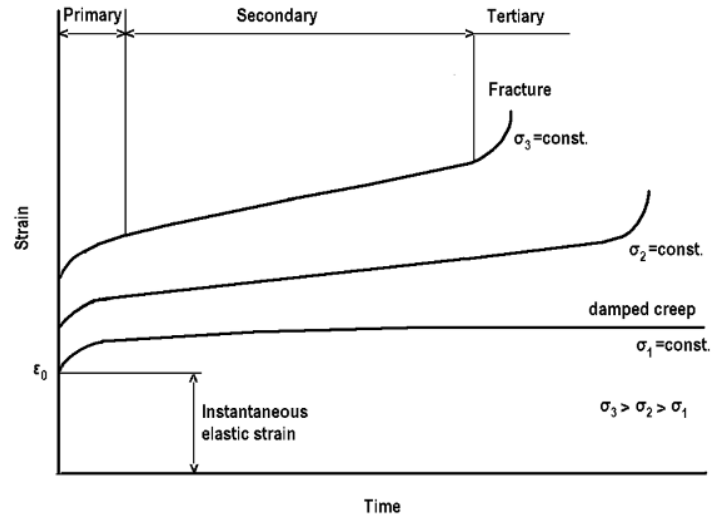

Figure 6. Typical Creep curves at static loading.

specimen immediately following the test initiation, was shown. This temperature increase had a hyperbolic form corresponds to the results of temperature changes during dynamic loading [4]. This temperature increase allows the termination of the decline in force necessary for maintaining the constant deformation. After the initial heating of the sample, the increase in temperature became stable and thus a decrease in force followed. After the the specimen relaxation, the temperature was intentionally raised, which showed itself in a marked increase in the force required for deformation maintenance. The fluctuating RED curve of the ambient room temperature is caused by the air conditioning in the room. In spite of running the air conditioning, a slight growth in temperature in the room during the test as well as its' effect on the relaxation curve is observable. This can explain the "atypical" behaviour of the relaxation curve in the initial phase and proves the negative effect of temperature changes on the accuracy of determining the rheological characteristics of rocks.

\section{Creep of rocks}

\subsection{Creep of rocks under static loading}

The creep of rocks is the ability of rocks to be strained through time without any change in load. In other words, we can observe the strain of a rock through time when a constant load is applied to it. An example of the typical development of creep at a static load, as given in the literature, is presented in Figure 6 below.

Figure 6 illustrates a typical creep curve for brittle rock showing the three phases of creep (the primary, secondary and tertiary). From this Figure it can be seen that, after

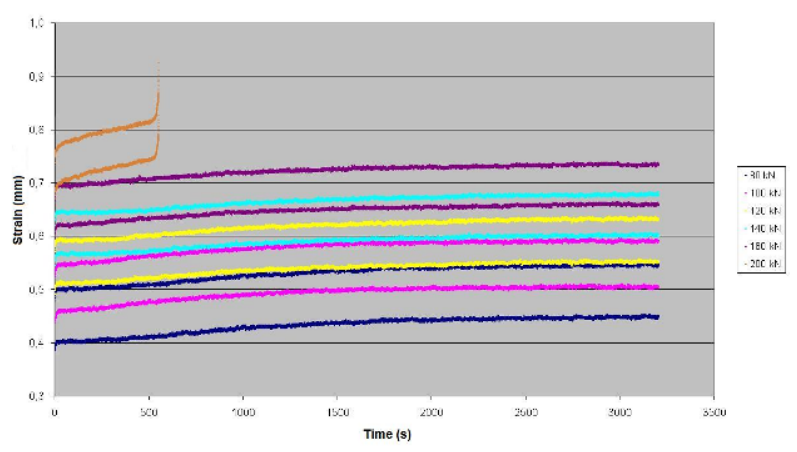

Figure 7. Comparison of creep curves at various TSP.

application of the load, there is an instantaneous elastic strain followed by a primary creep phase. The primary creep is followed by the secondary creep phase (steadystate) in which a permanent deformation occurs.

When various loading stresses are applied, multiple creep curves may be obtained for the same rock - see Figure 6. With the application of smaller loading stresses, after a certain time, the growth in strain stops so that avalanche creep will not occur, and thus, the rupture of the rock specimen will not take place. This is the case of damped creep. Damped creep will occur if the acting constant stress is less than or equal to the long-term strength. When the loading stress is larger than the long-term strength, the secondary creep phase will be succeeded by accelerated creep of the tertiary phase, leading to failure.

\subsection{Creep of rocks under cyclic loading}

In the study of the creep of rocks under dynamic loading, a number of tests where input values (TSP, amplitude, frequency) were varied, were individually conducted and then compared.

Initially, creep curves of sandstone at various values of TSP were tested, all with amplitude, $A=20 \mathrm{kN}$ and frequency, $f=5 \mathrm{~Hz}$. These tests were then compared. The value of the first TSP was $80 \mathrm{kN}$. During other tests the value of TSP was increased gradually to the rupture of the specimen. The results of the creep curves at various TSP is shown in Figure 7. From Figure 7, the instantaneous elastic strain that takes place immediately after loading is evident. After that, the phase of primary and secondary creep follows. At first, the creep is usually moderately damped by a growth in the temperature of the rock specimen under dynamic loading (see above). The majority of curves plotted at the lower TSP values will be damped. At 


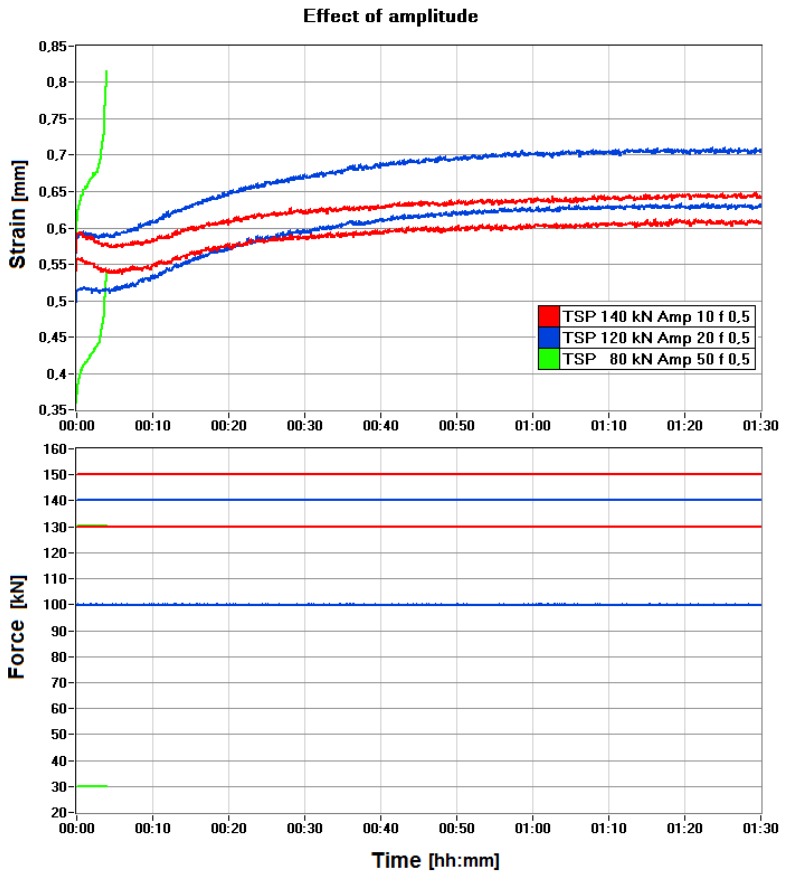

Figure 8. Effect of amplitude on rock creep.

the TSP value of $200 \mathrm{kN}$, damping did not occur and after a relatively short time, steady creep (secondary phase) passed into avalanche creep (tertiary phase), which led to the rupture and loss of cohesion of the sample.

The effect of amplitude size on rock creep was also studied. Here, the values of TSP and frequency were kept constant, while the amplitude was varied. An example of a graphic record of Godula sandstone creep in is given in Figure 8. From the Figure, the effect of amplitude size can be seen. At lower values of amplitude the creep of rock specimen was gradually damped, whereas at higher values of amplitude, the sample was ruptured after a relatively short time. This was so, even when the maximum force was lower than for the force in the case of the sample with the lower amplitude (see Figure 8).

In addition, the effect of loading frequency on rock creep at an otherwise equal setting of TSP and amplitude was observed and evaluated. For this evaluation, a special software application enabling comparison of records of various frequencies, was developed. The software enables the calculation of average levels of peaks $\left(\varepsilon_{p}\right)$ and valleys $\left(\varepsilon_{v}\right)$ per 1 second according to equation (1). These recalculated values correspond to a frequency $1 \mathrm{~Hz}$ so that they can be compiled in one graph and compared.

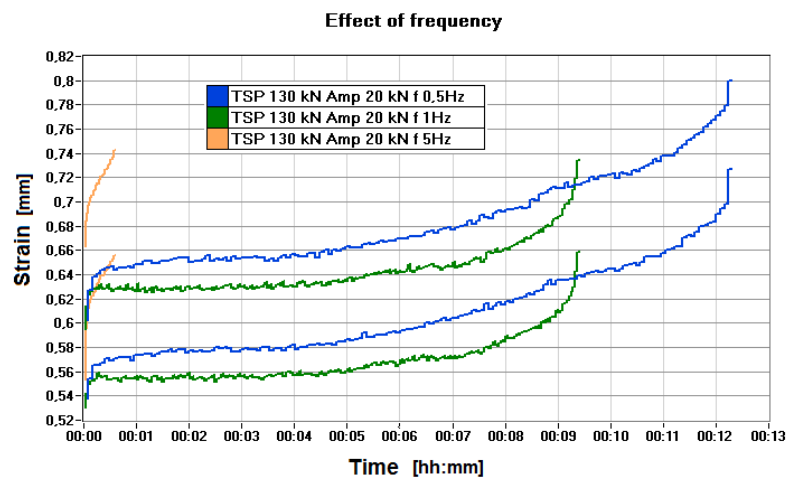

Figure 9. Effect of frequency on rock creep (brittle rock).

$$
\bar{\varepsilon}_{p}=\frac{\sum_{1}^{f} \varepsilon_{p}}{f}
$$

$\bar{\varepsilon}_{p}$ average value of peaks corresponding to frequency $1 \mathrm{~Hz}$,

$f$ actual (adjusted) frequency,

$\varepsilon_{p}$ instantaneous values of peaks.

The evaluation of the impact of frequency on the rock creep has proven to be the most difficult. The main problem was that the impact of frequency is not clear. This is supported by frequently contradicting results of various other published studies. Most authors tend to support the conclusion that, as the frequency decreases, the plastic deformation phenomena increases $[1,7]$. Other studies have shown that the impact of frequency compared to the impact of the amplitude is either negligible or is impossible to determine with any accuracy $[3,10,17]$. The studies in question have shown that the frequency is probably dependent on the degree of loading and the type of rock. With heavy loading and strong or brittle types of rock, the frequency increase is characterized by a rapid transfer into the third stage of creep, leading to sample failure. (See Figure 9.) This phenomenon can be explained on the basis of the above mentioned theory by Scholtz et al. $[1,6,8]$, who claim that rock corrosion at cyclic loading is the consequence of combining two mechanisms, i.e. stress corrosion and cyclic fatigue, running in parallel lines and independently of each other. At high levels of loading, the threshold load is exceed so that stress corrosion can cause the growing of tensile microcracks, which spread quickly due to the process of cyclic fatigue.

Conversely, at low levels of loading (TSP under longterm strength) or for more plastic rocks, the increase of frequency caused the manifestations of creep to diminish. See Figure 10. This can be explained by the fact that no cracks appear at low strain levels, under the stress 


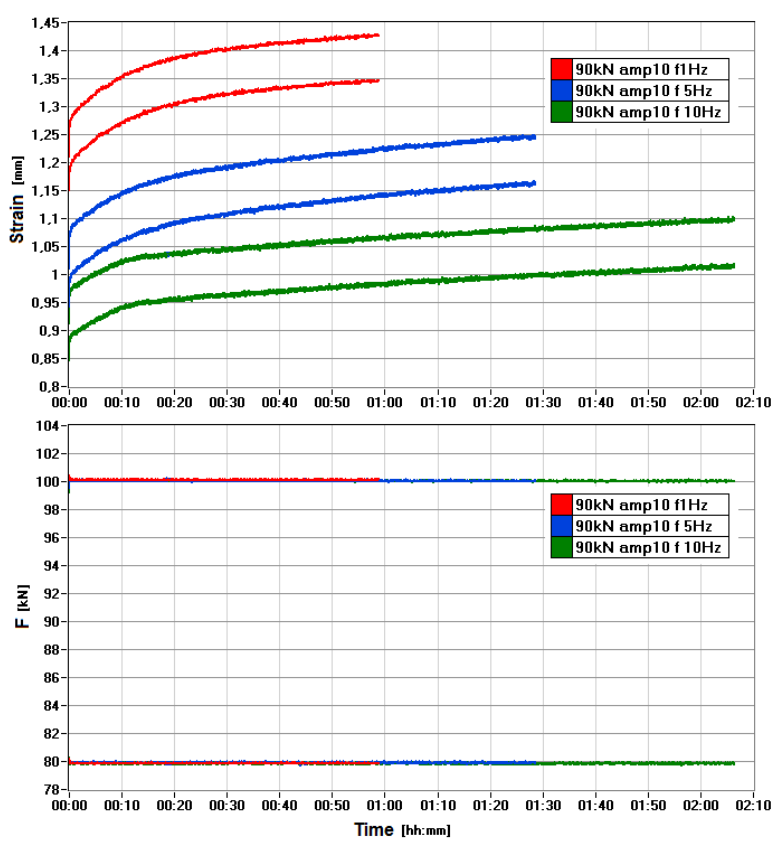

Figure 10. Effect of frequency on rock creep (plastic rock).

threshhold, or in the rocks that demonstrate plastic behaviour. There is only a viscoplastic rock transformation which is more common for slower loading, i.e. at lower frequencies [18]. This explanation correlates with formerly published findings [1,7] on rock behaviour under cyclic loading, which also shows that low frequency and high amplitude cycles accelerate the development of viscoplastic strains.

\section{Conclusion}

Research into the properties of rocks subject to dynamic (cyclic) loading is important for the better understanding of processes taking place in the course of anomalous geo-mechanical events in a rock mass. In this article, findings from research into rocks subjected to this kind of loading were summarised. According to the research, it has been confirmed that, although rock behaviour under a cyclic load in a rheological regime is similar to that under a static load, it depends on the parameters of loading, namely both on the load amplitude and frequency.

The factor which has the greatest impact on rheological rock properties is amplitude. As the amplitude grows, the time, before the sample failure, shortens. This is so, even when the maximum values of loading with a higher amplitude value do not reach the maximum loading values with a lower amplitude. It is therefore possible to claim that rocks can be ruptured even when the rock is exposed to regular unloading. This condition can arise, for example, in coal mining, when using the method of long-wall mining with caving. During this process, the stress in a rock mass is regularly increased before caving and decreased after caving [19]. Therefore, the rock mass is loaded cyclically, with a high amplitude and low frequency. The results of this research show that this kind of loading appears to be the least suitable.

The author has also tried to clarify the impact of loading frequency on the rheological behaviour of rocks. The results of this research show that frequency affects the behaviour of rocks. Nevertheless, the frequency impact depends on the middle loading value (TSP) and probably also on the size of the amplitude. If the rock is loaded above the threshold level when tensile cracks appear in it, then the increasing frequency has a negative impact on rock corrosion, and in vice versa.

Moreover, the research has confirmed that one of the basic requirements of long-term tests on rock samples is to maintain the constant state of the test environment, especially a constant temperature. To avoid errors caused by a change in temperature, it is recommended that continuous observation of the temperatures of the rock and also the surroundings, be carried out for future measurements.

What is important is the knowledge that the energy consumed by heating the rock subject to loading is due to the conversion of deformation energy, as is shown at the start/initiation of the relaxation curve.

\section{Acknowledgments}

This study was prepared thanks to support provided by the grant project GAČR 105/08/P307. This article also has been written in connection with the project Institute of clean technologies for mining and utilization of raw materials for energy use, reg. no. CZ.1.05/2.1.00/03.0082 supported by the Research and Development for Innovations Operational Programme financed by Structural Founds of Europe Union and by the means of state budget of the Czech Republic.

\section{References}

[1] Gatelier N., Pellet F., Loret B., Mechanical damage of anisotropic porous rock in cyclic triaxial tests. Int. J. Rock Mech. Min., 2002, 39, 335-54 
[2] Bagde M.N., Petroš V., Fatigue properties of intact sandstone samples subjected to dynamic uniaxial cyclical loading. Int. J. Rock Mech. Min., 2005, 42, 237-250

[3] Bagde M.N., Petroš V., The effect of machine behaviour and mechanical properties of intact sandstone under static and dynamic uniaxial cyclic loading. Rock Mech. Rock Eng., 2005, 38, 59-67

[4] Petroš V., Šancer J., Kadlec Z., Research of energy distributioin during dynamic loading of rocks. In: Grossmann N., Ribeiro E Sousa L., Olalla C. (Eds.), Proceedings of 11 th congress of the International Society for Rock Mechanics, Lisbon, Portugal, 9-13 July 2007, D. Stead \& T. Morrison, Taylor \& Francis, London, 2007, 1167-1172

[5] Pospíšil P., Cretaceous sandstones in Moravia and Silesia and their application as building and ornamental stones. B. Geosci., 2004, 79, 183-193

[6] Falaleev G.N., Rock creep degree assessment. J. Min. Sci., 2010, 46, 1, 34-37

[7] Scholz C.H., Koczynski T.A., Dilatancy anisotropy and the response of rock to large cyclic load. J. Geophys. Res., 1979, 84, 5525-5534

[8] Costin L.S., Holcomb D.J., Time-dependent failure of rock under cyclic loading. Tectonophysics, 1981, 79, 279-296

[9] Zhenyu T., Haihong M., An Experimental Study and Analysis of the Behaviour of Rock Under Cyclic Loading. Int. J. Rock Mech. Min., 1990, 27, 51-56

[10] Fuenkajorn K., Phueakphum D., Effects of cyclic loading on mechanical properties of Maha Sarakham salt.
Eng. Geol., 2010, 112, 43-52

[11] Atkinson B.K., Meredith R.G., The theory of subcritical crack growth with applications to minerals and rocks. In: Atkinson B.K. (Ed.), Fracture mechanics of rock. Academic Press, London, 1987, 111-166

[12] Potyondy D.O., Cundall P.A., A bonded-particle model for rock. Int. J. Rock Mech. Min., 2004, 41, 1329-1364

[13] Jeon H.S., Kang S.S. Obara Y., Influence of surrounding environments and strain rates on strength of rocks under uniaxial compression. Int. J. Rock Mech. Min., 2008, 4, 21-24

[14] Damjanac B., Fairhurst Ch., Evidence for a Long-Term Strength Threshold in Crystalline Rock. Itasca Counsulting Group Inc., 2009

[15] Potyondy D.O., Simulating stress corrosion with a bonded-particle model for rock. Int. J. Rock Mech. Min., 2007, 44, 677-691

[16] Badge M.N., Petroš V., Waveform Effect on Fatigue Properties of Intact Sandstone in Uniaxial Cyclical Loading. Rock Mech. Rock Eng., 2005, 38, 169-196

[17] Tien Y.M., Lee D.H. Juang C.H., Strain, Pore Pressure and Fatigue Characteristics of Sandstone under Various Load Conditions. Int. J. Rock Mech. Min., 1990, 27, 283-89

[18] Fabre G., Pellet F., Creep and time dependent damage in argillaceous rocks. Int. J. Rock Mech. Min., 2006, 43, 2006, 950-960

[19] Jiránková E., Assessment of rigid overlying strata failure in face mining. Central European Journal of Geosciences. 2010, 2, 524-530 